\title{
METHODS OF EVALUATING INTERNATIONAL RISKS IN THE INSURANCE MARKET
}

\author{
[Způsoby hodnocení mezinárodních rizik na pojišt’ovacím trhu] \\ Michaela Petrová ${ }^{1}$, Martina Krügerová ${ }^{2}$, Michal Koziel ${ }^{3}$ \\ ${ }^{1}$ VSB - Technical University of Ostrava, Faculty of Economics, Sokolská třida 33, 70121 Ostrava \\ ORCID 0000-0003-0979-3046 \\ Email: michaela.petrova@vsb.cz \\ ${ }^{2}$ VSB - Technical University of Ostrava, Faculty of Economics, Sokolská třída 33, 70121 Ostrava \\ ORCID 0000-0001-5049-8183 \\ Email: martina.krugerova@vsb.cz \\ ${ }^{3}$ VSB - Technical University of Ostrava, Faculty of Economics, Sokolská třída 33, 70121 Ostrava \\ ORCID 0000-0001-8561-0358 \\ Email: michal.koziel@vsb.cz
}

\begin{abstract}
Today, insurance companies are looking for new approaches to risk insurance so that the risk remains insurable and at the same time does not endanger the existence of the insurance company itself. Every risk must be evaluated by the insurance company as best as possible. Insurance companies have their own methodologies for assessing international risks, which show differences. Each insurance company tries to ascertain the most accurate quantitative and qualitative data in order to analyse the potential risk in depth. Evaluation is the basis for setting prices, country risk limits and, if necessary, has an impact on the specific definition of risk acceptance conditions. The aim of the article is to analyse and evaluate the methods and approaches of insurance companies on the basis of data obtained from databases of OECD and selected credit insurance companies. Further assess from the perspective of the exporter whether these methods are important in his deciding during the implementation of a specific business case. The result is the finding that the risk evaluations of insurance companies are beneficial for the exporter in terms of assessing the planned intention to export to the territory.
\end{abstract}

Keywords: export, insurance market, international risk.

JEL classification: F13, F36, F53, K33

Received: 5.10.2020; Reviewed: 28.10.2020; 2.12.2020; Accepted: 16.12.2020

\section{Introduction}

In the prepared business cases export companies assess potential risks that may negatively affect the progress of orders. From the very relationships between business partners, there are risks for both parties that are desirable to minimize. These are really the same or similar to the Czech and international environment. However, in the case of exports, other risks come into play with an international overlap, which may already be more difficult to assess in terms of obtaining data and their correct evaluation. The exporter obtains information about potential business partners in order to minimize the risk, which is more complicated in an international environment, such as the risk of non-acceptance of the contract, and especially the risk that the customer will not be willing or able to pay. It also assesses the competition, local market, but also cultural or religious beliefs that may affect the business cooperation. From the point of view of export, important information is the country to which we want to export goods. The basic risks that can occur in a given country include a bad political situation, a state of war, terrorism, strikes, riots, etc. As reported by Böhm, Janatka (2004), information about business partners and associated territorial and commercial risks have become an important tool of risk management. 
Studies show that it is necessary to monitor the impact of international risks from different perspectives. Bar-Niv, Bickelhaupt (1986) in their study reviewed research in international risk management and insurance. The result is their classification according to purpose, methodology, perspective with a division into fifteen types of research. At the same time, they outline other directions of research in the field of international risks. Polák, Beranová, Tabas (2011) classify risks in international trade and assess the possibilities of assessing partial risks that are part of commercial risk. Due to the nature of variables and data obtained in the field of international risks, they consider, that it is appropriate to use static methods, especially regression analysis methods. They consider the use of fuzzy modeling to be necessary in the evaluation of business morale, when it is assumed that the obtained data will be of a qualitative nature. Lee, Chiu, Chang (2013) examines the relationship between countries' political, financial and economic risks and insurance demand. Glova, Bernatík, Dancáková (2019) also consider investing in a country where the risk depends on changes in the macroeconomic and business environment. They use cluster analysis to evaluate and test the significance of selected political and economic factors and their impact on country risk.

The exporter must also decide on the appropriate way to hedge the risks. Against individual risks, exporters can use insurance offers from commercial insurance companies or use insurance with state support. However, not all risks can be insured, therefore each risk should also be seen in terms of insurability and uninsurability on the Czech market (in detail Petrová 2020).

Export companies can assess the risks themselves or they can use specialized institutions. (Mortanges, Allers 1996). There are a number of global rating agencies or platforms that assess international risks from various perspectives. For example, The PRS Group's International Country Risk Guide (ICRG) includes political, economic and financial data in its assessment. The summary rating is updated monthly (for more see PRS Group). According to the PRS group (2020), this is the only methodology that assesses political risks and at the same time is adopted by the courts in commercial disputes concerning the assessment of political risks. Hoti (2003) in his arti cle uses and evaluates the International Country Risk Guide on the example of four developing countries. CountryRisk.io, as an independent online platform, provides its members the country risk assessment results and selected reports. CountryRisk.io uses a hybrid credit risk assessment model that combines statistical and heuristic elements; offer several indices for standard, ESG and anti-money laundering (AML) sovereign risk, include the UN Sustainable Development Goals (SDGs) Index. (see https://countryrisk.io/). Of course, the accuracy of assessors and evaluations by individual agencies must always be compared and evaluated, as stated by Asiri, Hubail (2014); McAleer, Hoti (2004).

Also, in the insurance sector, entities that offer solutions related to the international environment, specialized insurance companies or insurance intermediary compile their own risk maps in order to offer the best possible credit insurance solutions worldwide. Assuming that in most cases, export companies use an insurance company to hedge risks, can exporters use insurance companies' information directly? Then it is desirable to assess the risk assessment directly by insurance companies. The aim of the article is to evaluate the methods of analysing the export markets of insurance companies. According to our findings, the studies do not deal with the examination and comparison of individual methods of credit insurers, whereby the authors fill a gap in the field of this research. At the same time, information for the assessment of territorial risks can have a significant importance for both insurers and exporters. The parameters of the setting of insurance products and subsequent insurance rates depend on the riskiness of the given country, and they can influence the exporter's decision regarding a specific trade. The authors examine the evaluation methodology of selected entities and assess 
the differences in the resulting country risk indexes. Furthermore, to assess from the exporter's point of view the possible benefits in its decision-making during the implementation of a specific business case. By analysing export markets, insurance companies can also help exporters identify not only risks but also opportunities. Due to the focus of the article, the data of specialized credit insurance companies providing services in the Czech Republic will be used.

\section{Theoretical background - methods of international risk assessment by selected insurance companies}

When offering a set of specialized insurance products, insurance companies must assess and evaluate various parameters, including the riskiness of a given business case with respect to the country of export. Insurance companies must have access to provide reliable information sources, economic information and indicators. On this basis, then regularly evaluate the risks and determine the parameters of insurance products. However, the methods must respect defined international rules. The basic international risk assessment is based on a territorial risk assessment. This is evaluated uniformly and is based on the OECD Consensus.

There are several insurance companies that provide risk insurance in international trade for Czech exporters. Insurance companies operating on the Czech market are multinational specialized credit insurance companies.

- Coface - Compagnie Francaise D'Assurance Pour Le Commrce Exterieur Czech branch - offers services in the field of receivables insurance, risk management and the global economy. The insurance company assesses the financial risks of business cooperation and thus contributes to the development and protection of business relations.

- Euler Hermes SA, organizational unit - it was the first specialized private credit insurance company in the Czech Republic. The company is part of the Euler Hermes, AGF and Allianz groups. The insurance company specializes in qualified assessment of domestic risks and subsequent recovery of receivables.

- Atradius Crédito y Caución S.A. de Seguros y Reaseguros, a branch for the Czech Republic - provides services primarily in the field of receivables insurance, guarantees and debt collection services with operations worldwide.

- Credendo - Short-Term EU Risks credit insurance company, S.A. - is a subsidiary of the insurance company Credendo - Export Credit Agency, which provides professional services for exporters exporting their goods to emerging markets around the world.

The above companies are one of the largest specialized credit insurance companies operating worldwide. Credit insurers are associated in associations, such as Berne Union or ICISA. The International Union of Credit and Investment Insurers (Berne Union) brings together institutions in the export credit and investment insurance sectors. The International Credit Insurance \& Surety Association (ICISA) brings together the world's leading companies that provide trade credit insurance and/or surety bonds.

According to the AU Group (2020) and its market research (data for 2019), Euler Hermes has the largest share of the world market. 
Figure 1: Division of the world credit insurance market

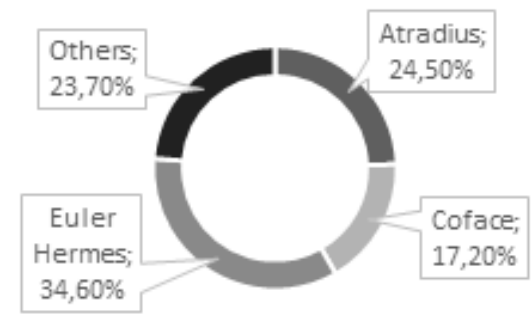

Source: AU Group [online] [cit. 1.September 2020]. Accessible from <https://tcisigorta.com/media/0hloxo2c/credit-insurance-market-2020-au-group.pdf >.

Figure 1 shows that more than $75 \%$ of total premiums in the commercial credit insurance market are represented by three credit insurers - Atradius (24.5\%), Coface (17.2\%) and Euler Hermes $(34.6 \%)$. The remaining third of the market is shared by the remaining market players. Credendo Insurance operates in selected geographical areas.

Due to the perspective of the Czech exporter, the EGAP insurance company was also included in the examined sample of world insurance companies, which offers both state support for exports and commercial insurance against commercial risks, like other insurance companies. Export Guarantee and Insurance Corporation, a.s. (EGAP) is a credit insurance company focusing on non-marketable political and commercial risks associated with financing the export of goods, services and investments from the Czech Republic.

\subsection{OECD methodology}

The risk assessment at OECD level (2020a) is not only based on the Consensus, but also in the context of the agreement on minimum premium fees for official export credits. Since 1997, a united risk classification methodology has been introduced to assess country credit risks. Since the methodology was introduced in 1997, before this year there is no historical classification. This classification always reflects the risk of the country and is created in order to set minimum insurance rates. It is therefore one of the basic building blocks for setting rules for minimum credit risk insurance arrangements, which are published for the purpose of compliance with the states who are not members or participants of the OECD Arrangement.

The country risk classification is reassessed and updated several times a year. There is always a group of experts from export credit agencies who review the riskiness of countries. Countries should be reviewed whenever there is any fundamental change. If there is no significant change, the country must be reviewed at least once a year. The date, place and order of individual meetings are always set in advance for the upcoming year. Meetings are always strictly confidential. It is important to reach an agreement between experts at the meeting. If no agreement is reached, the chairperson decides and the country must be re-examined at the next meeting. The result of these negotiations is a list of country risk classifications, which is publicly available on the OECD website. The results are final and are not subordinate to any confirmation, review or modification by the parties to the agreement. They automatically enter into force after the end of the meeting. (OECD 2017). The methodology includes the risk of transfer and convertibility, which is the risk that prevents the transfer of local currency to a foreign currency or the transfer of funds to creditors established outside the country. In addition, it includes the so-called force majeure, which includes, for example, war, civil unrest, revolution, expropriation, earthquakes, floods, etc. We can say that all territorial risks in the general sense are taken into account in the methodology, as they are defined in most literatures (Polák, Beranová, Tabas 2011; Bar-Niv, Bickelhaupt 1986; Böhm, Janatka 2004). 
The OECD (2020a) classifies country risks by using a two-stage methodology - a quantitative model and a qualitative model. The model is graphically illustrated in Figure 2. The first is the use of a quantitative model, which was created specifically for this purpose. This is the CRAM model - Country Risk Assessment Model. This model uses a total of three groups of risk indicators - payment experience reported by participants (payment experience is provided by all OECD export credit companies), the financial situation and the economic situation primarily based on IMF indicators. Thanks to this model, the country's credit risk is quantified. In the second step, there is a qualitative assessment of the CRAM results in order to add factors that the model in the first step does not take into account (such as the political situation in the country). This could lead to a change from the CRAM results, either to deterioration or improvement. Which means, CRAM uses both a quantitative and a qualitative approach to obtain the best possible qualification.

Figure 2: CRAM model

Experience with payments reported by participants
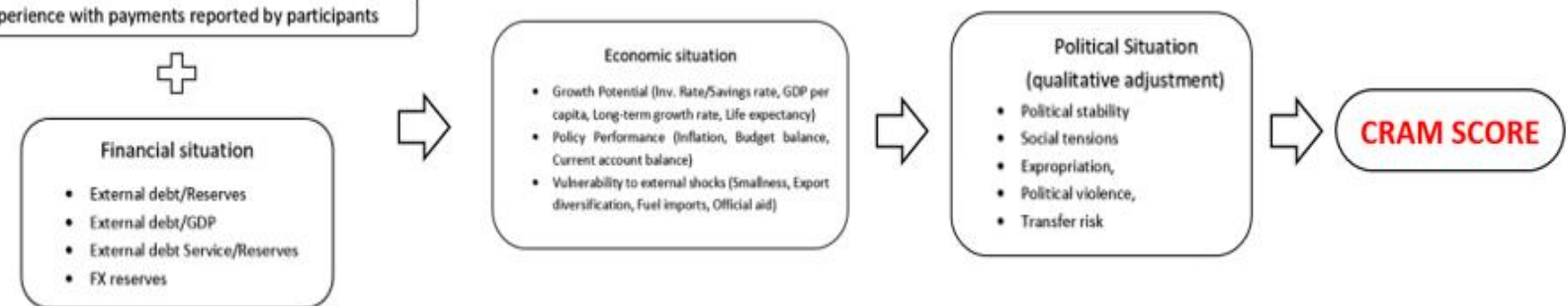

Source: OECD (2020a), own elaborating [online][cit. 15.July 2020]. Accessible from $<$ http://www.oecd.org/trade/topics/export-credits/arrangement-and-sector-understandings/financing-terms-andconditions/country-risk-classification/>.

Thanks to this methodology, countries are then included in one of eight categories (0-7). Category 0 is made up of countries such as the USA, Japan or EU countries and these are countries where no territorial risk is expected. In contrast, category 7 represents the countries with the highest risk (Montenegro, Ethiopia, Argentina...). But there are countries that are not classified. There are two groups of countries (OECD, 2017):

1) Small countries that do not receive official export credit support. These countries are not classified for the need to minimize administrative burdens, and moreover, the empirical basis on which CRAM results are based is not always complex for some very small countries. Here, participants can use the risk classification they consider appropriate.

2) High-income OECD countries and other high-income euro area countries.

Territorial risk factors based on the CRAM methodology are also taken into account when determining the Minimum Premium Benchmark (MPB) and Commercial Interest Reference Rates (CIRR).

\subsection{Coface}

Coface assesses risks from several perspectives, namely country risk, industry risk and the business climate (data are freely available). The basic assessment is based on an assessment of the average risk of non-payment by the business entity in the country. It combines views of economic, financial and political risk, and adds Coface's payment experience and assessment of the country's business climate. The company monitors the payment default of insured customers, when clients are obliged to state unpaid receivables in a specified number of days overdue. This is reflected in the Coface Payment Incident Index. The result is the publication of the Country Risk Assessment Map (Coface 2020a). Coface now includes environmental risks 
in its country risk assessment methodology. It divides the country risk into a scale of 8 levels: A1, A2, A3, A4, B, C, D, E (A1 very low - E extreme risk). A quarterly update of the evaluated 160 countries is a matter of course. It is also possible to compare the risks of selected countries, which can help exporters in their decision-making.

Coface further analyses the industry risk in terms of the average risk of non-payment by the business entity in the industry, in terms of industry developments and the financial situation of the entities. The evaluation is again quarterly, when 13 sectors are evaluated, from six geographical regions. The indicator is based on the dependence of five financial indicators (Coface 2020a): changes in revenue, profitability, the net debt ratio, cash flow, and claims observed by our network.

Coface has developed its own forecasting tool for its evaluations: CRAFT (Coface Research Activity Forecasting Tool). It is based on the statistical method of Principal Component Analysis (PCA), which is one of the basic methods of variable extraction. Coface uses machine learning models to determine and extract variables. The variables that are most likely to affect economic activity are gradually extracted between thirty and fifty for each country. They can be divided into four different categories: hard data, survey data, monetary and financial variables, and international indicators. To these four variables, Coface now adds data related to credit insurance - the company's default rate for trade receivables insured by Coface in aggregate by country. The CRAFT tool enables correct GDP projections for the current quarter (now) and for the next quarter (forecasts). (Coface 2020b)

Coface operates the client's online platform InfoIcon, through which it offers its clients a number of useful information that can help them choose business partners or analyze potential risks of both partners and export countries. The Coface monitoring system uses a unique database that contains information on more than 145 million companies in more than 40 countries in Europe and the USA. (Coface 2020c) Companies can monitor their business partners and reduce the risks associated with trading with them. Within the Coface Risk Monitor platform (and the required level of information), the exporter can find out basic data about the partner sought, information about the company's management, key financial indicators, exchange rates, based on further analysis, a quick evaluation of the company. (Coface 2020c) The Coface Risk Monitor platform evaluates up to 28 monitoring criteria and informs clients about changes in the monitored criteria. (Coface 2020d) The monitored criteria include insolvency, creditworthiness - rating score and its trend, payment morale, out-of-court collection, turnover, number of employees, equity. By evaluating criteria and sending change notifications, the exporter can respond in a timely manner to avoid unwanted problems. The Coface Business Finder platform searches the largest database in Central and Eastern Europe through which the company can search for its future business partners and find out the necessary information. An exporter can search for and expand its database with new business partners. The advantage for exporters is that the companies in the system have already been credit checked by Coface. Alternatively, in-depth industry analysis and risk management information in the selected sector can be obtained. (Coface 2020e) Within the Coface Cross Boarder Network, exporters can then check the most important domestic and international business contacts in the region of Central and Eastern Europe from an internal perspective. In the Covid19 crisis situation, Coface (2020c) offered its InfoIcon online platform free of charge for three months. 


\subsection{Credendo}

Credendo also conducts an in-depth analysis of each country and the different types of risks. The results of this analysis are the basis for setting prices, country risk limits and possibly to determination of specific conditions of risk acceptance.

Credendo uses different risks to classify countries depending on whether they are business (export) transactions or direct investments abroad (Credendo 2020):

- Export transactions

- Political and assimilated events

- short-term political risks

- medium-term/long-term political risk

- Commercial risks

○ Direct investments

- Political violence risks

- Expropriation risks

- Currency inconvertibility and transfer restriction risks

In terms of the focus of this article, we are interested in risk assessment for export transactions, such as domestic and international sales of goods or services, contract transport, pre-financing, guarantee insurance, etc.

The insurance company classifies in political risks all risks involving force majeure such as war, riots, revolutions, natural disasters or lack of foreign exchange. Country classifications are regularly updated and individual countries are reassessed as needed. As a result, countries are divided into a total of 7 categories according to the intensity of risk - category 1 consists of countries with the lowest risk and category 7 consists of countries with the highest probability of risk caused by political and assimilated events. Credendo (2020) distinguishes its classification of political risk according to another factor, and that is the duration of this risk. The risk of events that may occur within one year is considered to be short-term, over one year it is medium-term or long-term risk.

A quantitative model is used to assess short-term political risk, where the development of the debtor's liquidity is monitored. It therefore monitors whether a country is able to meet its payment obligations. The model also observes the qualitative aspect, specifically any deterioration or improvement in the situation of the countries concerned. In order to allow frequent updating and relevance, the rating has only a limited number of indicators - three standard liquidity indicators (short-term external liabilities, foreign exchange reserves, current account balance), refinancing indicators and the short-term political situation (war, embargo). Other relevant factors and information that standard economic indicators do not include may be included.

In assessing medium and long-term political risk, Credendo uses a model to measure a country's solvency, assessing the economic situation, financial situation, political situation and payment experience analysis for each country. The economic situation is assessed using a total of three groups of indicators - economic policy performance indicators (fiscal and monetary policy, external balances and structural reforms), indicators reflecting the country's growth potential (savings, investment quotas, growth performance) and external vulnerability indicators (export diversification, aid dependency). The financial situation is assessed according to external debt ratios (foreign debt) and some liquidity indicators - foreign exchange reserves. Quantitative indicators are also used to determine the political situation. Data on payment experience are 
obtained both by the company itself and on the basis of data from other credit insurance companies within the OECD.

Commercial risks are risks arising from the default of a business partner. Credendo (2020) assesses the risk of debtor default by assessing the risk of the debtor on a case-by-case basis and also by assessing the business sector and the country in which the debtor is active. The solvency of a debtor in a given country also depends on some macroeconomic factors, such as a sharp currency depreciation, high real interest rates, an economic recession, widespread corruption. That is why Credendo also assesses macroeconomic risks, which it calls systemic commercial risk. The model that Credendo uses to classify these risks consists of three types of indicators - economic and financial indicators (exchange rate volatility, local financial costs, economic cycle, inflation,...), indicators that take into account the country's payment experience based on debtor default, and indicators characterizing the institutional context in which local companies operate (corruption, quality of the legal system). After classification, the countries are divided into three categories - A, B and C. Category A consists of countries with low commercial risk and category $\mathrm{C}$, on the other hand, countries with above-average commercial risk. The evaluation is regularly updated and reassessed as necessary. In addition to classifying countries by risk, Credendo also has access to a large amount of data from around the world, both from its clients and from other available sources, and therefore the client has the opportunity to verify whether the selected customers are financially reliable. Up to three customers can be verified in this way without obligation.

Credendo is also directly involved in setting minimum insurance rates under the OECD Arrangement on Officially Supported Export Credits. Credendo even chairs meetings of experts from export credit agencies who provide the OECD's territorial risk model, as described in Chapter 2.1.

\subsection{Atradius}

To determine the degree of country risk, Atradius (2020) takes into account a wide range of factors such as regulatory changes, the risk of property confiscation, civil unrest, war or currency devaluation. The evaluation also includes the willingness and ability of the government department of the country to pay, which affects the public's ability to pay its foreign liabilities.

Atradius assesses risks based on the STAR rating system. Various criteria are reflecting, including political and economic risks, civil unrest, conflicts or the financial situation of the government. STAR (from the English Sovereign Transfer and Arbitrary Risk) is a rating system that uses a rating on a scale from 1 to 10 divided into five categories: 1 and 2 low risk, 3 and 4 moderate-low risk, 5 moderate risk, 6 to 7 moderate-high risk, 8 to 9 high risk, 10 very high risk. Level 5 sets the line between what can still be considered an investment level and what is already in the speculation sector. (Atradius 2020) Sovereign transfer risk is the likelihood that a country will not be able to repay for economic or financial reasons. Arbitrary action risk is the second component, which then forms the overall STAR rating. This also assesses the likelihood of restrictions on private and public entities in fulfilling their payment obligations. However, the restrictions imposed by the sovereign and not by economic necessity are considered, which is closely related to the government's behaviour.

The STAR rating process consists of a comparative analysis of external ratings and an internal underwriter and economist assessment. External evaluation are assessments by large rating agencies of long-term sovereign ratings in foreign currency and the values are mapped to a 
given STAR rating scale. This external evaluation forms the basis of the market evaluation. The subscriber's internal evaluation is obtained through regular economic research.

For a better understanding of each level, the descriptive characteristics of the assessment political, economic and transactional risks - are analysed in more detail. Political risks are taken in the context of "sovereign stability" and these factors assess the overall political and security situation in a given country. Economic risks are characterized by indicators of "economic stability", which are ideas about economic balance and sustainability. Transactional (financial) risks are considered in the context of "transactional efficiency", which provides a broad assessment of the ability to repay debt in full and on time. Atradius also takes disaster risk into account in its analysis. They are trying to assess a country's ability to withstand economic and financial consequences of major natural disasters. All mentioned rating categories are evaluated and used to determine and adjust the rating and are considered to be Atradius' internal view of country risk. There is a strong dependence between the individual risk categories and the worst assessment of all risks affects the country's overall risk profile. (Atradius 2015)

\subsection{Euler Hermes}

Euler Hermes classifies countries into risk ratings based on two categories - the country's ongoing risk assessment - 4 levels, and the short-term business environment assessment - 6 levels. The ongoing Country Grade assessment takes into account macroeconomic risks, the business environment and the stability and effectiveness of the political system. The risk categories are low, medium, sensitive and high. The short-term Country Risk Level, on the other hand, reflects commercial and financial risks. (Euler Hermes 2020a)

The risk assessment methodology considers four categories in particular - demand, profitability, liquidity, and business environment and is a unique methodology that combines data and expert judgment. They are therefore based on both Euler Hermes' internal data and fixed data from secondary sources. Expert judgment is the responsibility of experienced credit analysts who monitor risks in companies around the world. Furthermore, it is necessary to evaluate trends in the industry, this is in the hands of sector consultants who form the Economic Research team. All internal data are collected on a quarterly basis using a questionnaire.

All four categories are analysed globally for each sector. Within demand, the turnover of companies based on the organic drowth, fundamentals and price competition of the sector are monitored. Profitability is assessed according to the margins and profits of companies in connection with the development of raw material and commodity prices, labour costs, fluctuations in supply and capacity. Liquidity is determined by companies' access to finance and solvency, and the business environment includes factors such as technological innovation, government subsidies and changes in the legal system. These sectoral risks then complement the Country Risk rating, but also the individual risk assessment of buyers. (Euler Hermes 2020b)

\subsection{EGAP - Export Guarantee and Insurance Corporation}

EGAP insurance company, in its main function, complements the offer of commercial credit insurance companies and fulfills the role of a state instrument to support exports. It provides insurance services to all exporters of Czech goods, services and investments. The evaluation of EGAP takes over the evaluation of the OECD methodology. However, EGAP also adds its own evaluation. The insurance company publishes the so-called EGAP barometer on its website, which has an A - F scale (6-point, compared to 8-point OECD). It is based on an internal evaluation of the insurance company, in which it includes the political, economic and financial 
situation of the country. The assessment of EGAP may thus differ from the official OECD categorization. As with other entities, EGAP also takes into account the payment experience of EGAP and partner export agencies in the OECD countries, the sovereign risk arising from the structure of the economy, the political situation, the legal, security and business environment, the banking sector and others. (EGAP 2020) According to the EGAP communication (2020), EGAP insures export transactions to all countries.

\section{Metodology and findings}

When offering a set of specialized credit insurance products, insurance companies must assess and evaluate various parameters, including the riskiness of a given business case in view of the country of export. Based on their own methodologies, they compile their own risk maps in order to offer the best possible credit insurance solutions worldwide. All insurance companies base their assessment on an OECD territorial risk evaluation, or they use OECD data. On this basis, however, each insurance company approaches its own methodologies and its own evaluation of experts. As can be seen from the description, insurance companies leave nothing to chance, and invest considerable resources in developing new procedures and expertise.

Common for all mentioned entities is the regular evaluation of the given risks and possible adjustments of the parameters of insurance products. Insurance companies also offer their own platforms that help exporters, for example, with choosing a business partner, obtaining basic information and verifying the financial stability of the partner. The information is available on the insurance companies' websites, selected platforms only for clients or after contacting and ordering the database from the insurance company.

Regarding the methodology used in the article - the authors compare the resulting international risk assessment published by selected entities, using analysis and synthesis (examination of individual aspects), abstraction and induction. The authors use available primary data from the OECD international risk assessment, and secondary data by global insurance companies offering credit insurance in the Czech Republic, namely Coface, Atradius, Credendo and Euler Hermes; last but not least, the credit insurance company EGAP, which complements the offer of commercial credit insurance companies with the role of a state instrument to support exports.

Table 1 is compiled to compare the resulting evaluations. We analyse evaluations in OECD countries. The reason is a comparison of the OECD methodology by other insurance companies. For individual subjects we use: in the case of the OECD it is a territorial risk assessment, in the case of EGAP we take into account EGAP barometer data, in the case of Coface Country risk assessment, in the case of Credendo the medium/long-term political risk classification, for Atradius the Country risk grade and, in the case of Euler Hermes the overall risk assessment was used (detailed in the explanatory notes to Table 1).

Table 1 uses freely accessible data from the evaluation of individual insurance companies described in the article. The reason is also the view of the Czech exporter, who could use this data to make his decision. For this experiment, the authors do not take into account the possibilities of paid services of individual insurance companies, which the exporter, in the opinion of the authors, would use in the second phase. 
Table 1: Risk assessment (data for 2020)

\begin{tabular}{|c|c|c|c|c|c|c|}
\hline OECD countries & OECD & EGAP & Coface & Credendo & Atradius & Euler Hermes \\
\hline Rating scale & $0-7$ & $A-F^{* 1}$ & $\begin{array}{c}\mathrm{A} 1, \mathrm{~A} 2, \mathrm{~A} 3, \mathrm{~A} 4 \\
\mathrm{~B}, \mathrm{C}, \mathrm{D}, \mathrm{E}^{* 2}\end{array}$ & $1-7^{* 3}$ & $1-6^{* 4}$ & $1-4^{* 5}$ \\
\hline Austria & 0 & $\mathrm{~A}(1)$ & $\mathrm{A} 2$ & 1 & 1 & 1 \\
\hline Belgium & 0 & $\mathrm{~A}(1)$ & A3 & 1 & 1 & 1 \\
\hline Canada & 0 & $\mathrm{~A}(1)$ & A3 & 1 & 1 & 1 \\
\hline Denmark & 0 & A (1) & A2 & 1 & 1 & 1 \\
\hline France & 0 & $\mathrm{~A}(1)$ & A3 & 1 & 1 & 1 \\
\hline Germany & 0 & $\mathrm{~A}(1)$ & A3 & 1 & 1 & 1 \\
\hline Greece & 0 & $\mathrm{E}(5)$ & $\mathrm{B}$ & 5 & 4 & 2 \\
\hline Iceland & 0 & $\mathrm{~A}(1)$ & A3 & 2 & 2 & 2 \\
\hline Ireland & 0 & $\mathrm{~A}(1)$ & A4 & 1 & 2 & 2 \\
\hline Italy & 0 & B (2) & $\mathrm{B}$ & 1 & 2 & 2 \\
\hline Luxembourg & 0 & A (1) & $\mathrm{A} 2$ & 1 & 1 & 1 \\
\hline Netherlands & 0 & $\mathrm{~A}(1)$ & $\mathrm{A} 2$ & 1 & 1 & 1 \\
\hline Norway & 0 & $\mathrm{~A}(1)$ & A2 & 1 & 1 & 1 \\
\hline \begin{tabular}{|l|} 
Portugal \\
\end{tabular} & 0 & B (2) & A3 & 1 & 2 & 1 \\
\hline Spain & 0 & B (2) & A3 & 1 & 1 & 1 \\
\hline Sweden & 0 & A (1) & $\mathrm{A} 2$ & 1 & 1 & 1 \\
\hline Switzerland & 0 & $\mathrm{~A}(1)$ & $\mathrm{A} 2$ & 1 & 1 & 1 \\
\hline Turkey & 5 & $\mathrm{D}(4)$ & $\mathrm{C}$ & 5 & 3 & 3 \\
\hline United Kingdom & 0 & $\mathrm{~A}(1)$ & A4 & 1 & 1 & 2 \\
\hline USA & 0 & $\mathrm{~A}(1)$ & A3 & 1 & 1 & 1 \\
\hline Japan & 0 & A (1) & $\mathrm{A} 2$ & 1 & 1 & 2 \\
\hline Finland & 0 & $\mathrm{~A}(1)$ & $\mathrm{A} 2$ & 1 & 1 & 1 \\
\hline Australia & 0 & $\mathrm{~A}(1)$ & A3 & 1 & 1 & 1 \\
\hline New Zealand & 0 & A (1) & $\mathrm{A} 2$ & 1 & 1 & 1 \\
\hline Mexico & 3 & $\mathrm{~B}(2)$ & $\mathrm{B}$ & 3 & 2 & 2 \\
\hline Czech Republic & 0 & A (1) & A4 & 1 & 1 & 2 \\
\hline South Korea & 0 & A (1) & A3 & 1 & 1 & 1 \\
\hline Hungary & 0 & B (2) & A4 & 3 & 2 & 2 \\
\hline Poland & 0 & $\mathrm{~A}(1)$ & A4 & 1 & 2 & 2 \\
\hline Slovakia & 0 & $\mathrm{~A}(1)$ & A4 & 1 & 2 & 2 \\
\hline Chile & 0 & $\mathrm{~A}(1)$ & A4 & 3 & 2 & 2 \\
\hline Slovenia & 0 & A (1) & A4 & 1 & 2 & 2 \\
\hline Israel & 0 & A (1) & A3 & 3 & 2 & 1 \\
\hline Estonia & 0 & A (1) & A3 & 1 & 2 & 1 \\
\hline Lithuania & 0 & A (1) & A4 & 2 & 2 & 2 \\
\hline Latvia & 0 & A (1) & A4 & 1 & 2 & 1 \\
\hline Colombia & 4 & $\mathrm{D}(4)$ & $\mathrm{B}$ & 5 & 2 & 2 \\
\hline
\end{tabular}

Source: OECD, EGAP, Coface, Atradius, Euler Hermes, Credendo

Legend: ${ }^{* 1}$ Evaluation according to the EGAP Barometer (the number for comparison with other insurance companies is given in brackets, starting with 1 after the letter A)

${ }^{* 2}$ A1 - very Low (1), A2 - Low (1,25), A3 - Satisfactory (1,5), A4 - Reasonable (1,75), B - Fairly High (2), C - High (3), D

- Very High (4), E - Extreme (5)

*3 The medium-/long-term political risk classification (1 - Low Risk to 7 - High Risk)

${ }^{* 4}$ Grade country risk $(1=$ Low risk, 2 = Moderate-low risk, 3 = Moderate risk, 4 = Moderate-high risk, 5 = High risk, $6=$ very High risk

${ }^{* 5}$ Overall risk assessment (grade country) - 4 levels from 1 to 4

For the purpose of comparing the ratings of individual insurance companies, the values were converted to percentage values (see Table 2), where a value of $0 \%$ means the lowest risk and a value of $100 \%$ means the highest risk. The recalculation was performed so that the minimum and maximum value was always reflecting for individual insurance companies, and these set the minimum and maximum percentage value. Subsequently, a recalculation was performed so that the outputs of the territorial risk assessment were mutually comparable. E.g. for Euler Hermes, the recalculation was that each country risk level corresponded to $33 \%$, with rating 1 corresponding to $0 \%$ risk, rating 2 corresponding to $33 \%$ risk, rating 3 corresponding to $66 \%$ risk and rating 4 corresponding to $100 \%$ risk. 
However, the recalculation should be taken only as a guide, because the individual ratings of insurance companies are very broad and involve a wide range of possible risks. In addition, completely different facts are often compared. Therefore, it is necessary to considering not only the comparison between individual insurance companies, but especially the comparison between the evaluations of individual countries within one insurance company, which has the same, if not greater, informative value. If we look, for example, at the Coface rating, none of the rated countries got to $0 \%$ risk, as is the case with other insurance companies. However, this does not mean that the level of risk is so different, it can only evoke that Coface's evaluation criteria are set more strictly and very few countries get to the lowest level of risk. In the case of Coface, it can also be caused by the fact that the company divides the country risk into a scale of 8 levels: A1, A2, A3, A4, B, C, D, E (A1 very low - E extreme risk). However, risk A is divided between four levels - A1, A2, A3, A4. In the recalculation, we therefore considered the division of risks into five levels (1-5), with the fact that we evaluated sub-levels A1, A2, A3 and A4 within one sub-level $(1 ; 1.25 ; 1.5 ; 1.75)$. In this case, the rating is more comparable with other insurance companies. The authors consider the distribution of level A as a strategy of the insurance company to evaluate relatively non-risk countries with higher sensitivity.

Table 2: Territorial risk assessment - recalculation

\begin{tabular}{|c|c|c|c|c|c|c|}
\hline OECD countries & OECD & EGAP & Coface & Credendo & Atradius & Euler Hermes \\
\hline Austria & $0 \%$ & $0 \%$ & $6 \%$ & $0 \%$ & $0 \%$ & $0 \%$ \\
\hline Belgium & $0 \%$ & $0 \%$ & $13 \%$ & $0 \%$ & $0 \%$ & $0 \%$ \\
\hline Canada & $0 \%$ & $0 \%$ & $13 \%$ & $0 \%$ & $0 \%$ & $0 \%$ \\
\hline Denmark & $0 \%$ & $0 \%$ & $6 \%$ & $0 \%$ & $0 \%$ & $0 \%$ \\
\hline France & $0 \%$ & $0 \%$ & $13 \%$ & $0 \%$ & $0 \%$ & $0 \%$ \\
\hline Germany & $0 \%$ & $0 \%$ & $13 \%$ & $0 \%$ & $0 \%$ & $0 \%$ \\
\hline Greece & $0 \%$ & $80 \%$ & $25 \%$ & $67 \%$ & $60 \%$ & $33 \%$ \\
\hline Iceland & $0 \%$ & $0 \%$ & $13 \%$ & $17 \%$ & $20 \%$ & $33 \%$ \\
\hline Ireland & $0 \%$ & $0 \%$ & $19 \%$ & $0 \%$ & $20 \%$ & $33 \%$ \\
\hline Italy & $0 \%$ & $20 \%$ & $25 \%$ & $0 \%$ & $20 \%$ & $33 \%$ \\
\hline Luxembourg & $0 \%$ & $0 \%$ & $6 \%$ & $0 \%$ & $0 \%$ & $0 \%$ \\
\hline Netherlands & $0 \%$ & $0 \%$ & $6 \%$ & $0 \%$ & $0 \%$ & $0 \%$ \\
\hline Norway & $0 \%$ & $0 \%$ & $6 \%$ & $0 \%$ & $0 \%$ & $0 \%$ \\
\hline Portugal & $0 \%$ & $20 \%$ & $13 \%$ & $0 \%$ & $20 \%$ & $0 \%$ \\
\hline Spain & $0 \%$ & $20 \%$ & $13 \%$ & $0 \%$ & $0 \%$ & $0 \%$ \\
\hline Sweden & $0 \%$ & $0 \%$ & $6 \%$ & $0 \%$ & $0 \%$ & $0 \%$ \\
\hline Switzerland & $0 \%$ & $0 \%$ & $6 \%$ & $0 \%$ & $0 \%$ & $0 \%$ \\
\hline Turkey & $71 \%$ & $60 \%$ & $50 \%$ & $67 \%$ & $40 \%$ & $66 \%$ \\
\hline United Kingdom & $0 \%$ & $0 \%$ & $19 \%$ & $0 \%$ & $0 \%$ & $33 \%$ \\
\hline USA & $0 \%$ & $0 \%$ & $13 \%$ & $0 \%$ & $0 \%$ & $0 \%$ \\
\hline Japan & $0 \%$ & $0 \%$ & $6 \%$ & $0 \%$ & $0 \%$ & $33 \%$ \\
\hline Finland & $0 \%$ & $0 \%$ & $6 \%$ & $0 \%$ & $0 \%$ & $0 \%$ \\
\hline Australia & $0 \%$ & $0 \%$ & $13 \%$ & $0 \%$ & $0 \%$ & $0 \%$ \\
\hline New Zealand & $0 \%$ & $0 \%$ & $6 \%$ & $0 \%$ & $0 \%$ & $0 \%$ \\
\hline Mexico & $43 \%$ & $20 \%$ & $25 \%$ & $33 \%$ & $20 \%$ & $33 \%$ \\
\hline Czech Republic & $0 \%$ & $0 \%$ & $19 \%$ & $0 \%$ & $0 \%$ & $33 \%$ \\
\hline South Korea & $0 \%$ & $0 \%$ & $13 \%$ & $0 \%$ & $0 \%$ & $0 \%$ \\
\hline Hungary & $0 \%$ & $20 \%$ & $19 \%$ & $33 \%$ & $20 \%$ & $33 \%$ \\
\hline Poland & $0 \%$ & $0 \%$ & $19 \%$ & $0 \%$ & $20 \%$ & $33 \%$ \\
\hline Slovakia & $0 \%$ & $0 \%$ & $19 \%$ & $0 \%$ & $20 \%$ & $33 \%$ \\
\hline Chile & $0 \%$ & $0 \%$ & $19 \%$ & $33 \%$ & $20 \%$ & $33 \%$ \\
\hline Slovenia & $0 \%$ & $0 \%$ & $19 \%$ & $0 \%$ & $20 \%$ & $33 \%$ \\
\hline Israel & $0 \%$ & $0 \%$ & $13 \%$ & $33 \%$ & $20 \%$ & $0 \%$ \\
\hline Estonia & $0 \%$ & $0 \%$ & $13 \%$ & $0 \%$ & $20 \%$ & $0 \%$ \\
\hline Lithuania & $0 \%$ & $0 \%$ & $19 \%$ & $17 \%$ & $20 \%$ & $33 \%$ \\
\hline Latvia & $0 \%$ & $0 \%$ & $19 \%$ & $0 \%$ & $20 \%$ & $0 \%$ \\
\hline Colombia & $57 \%$ & $60 \%$ & $25 \%$ & $67 \%$ & $20 \%$ & $33 \%$ \\
\hline
\end{tabular}

Source: OECD, EGAP, Coface, Atradius, Euler Hermes, Credendo 
Table 2 shows that, after the recalculation, the risk assessment for individual insurance companies differs very significantly in some cases. The OECD assessment, on which all other insurance companies are based, was used for comparison. In the case of EGAP, the authors use its modified methodology of the EGAP Barometer. The evaluation of the EGAP Barometer is significantly different from the OECD evaluation in several results. This is most evident in Greece, where they approach Credendo and Atradius in their ratings. However, for other insurance companies, it is clear that these add to the OECD assessment other internal assessments, which some countries classify in different categories than the OECD. From the performed comparison, Coface evaluates the most strictly, followed by Euler Hermes. It is also interesting to follow the ratings of individual countries at various insurance companies. Greece, for example, is assessed by the OECD as non-risk, but other insurance companies (with the exception of Euler Hermes and Coface) place it more at the centre of the risk spectrum, while EGAP ranks it among the most risky OECD countries. Greece, together with Turkey and Colombia, is based on the comparison as one of the riskiest countries.

\section{Discussion}

Freely accessible data from the methodologies of selected insurance companies are used in the evaluation, namely EGAP, Atradius, Coface, Credendo and Euler Hermes. For comparison, the authors use the OECD evaluation methodology. These are data that a Czech exporter could use for initial expertise. Insurance companies also offer various discounted platforms accessible only to clients, or even to the public, whether free or paid. This is additional data that the exporter can use in the next phase of his decision-making process.

The resulting comparison of country risk assessments shows that insurance companies approach the assessment systematically. They use their own internal evaluation mechanisms, using OECD data as a source of primary data. To these are added the evaluation of other aspects, especially the political situation, legal, security and business environment, the state of the banking sector, own payment experience and payment experience of partner export agencies, sovereign risk arising from the structure of the economy and more. Glova, Bernatík, Dancáková (2019) in their analysis list the main factors influencing country risk: the GDP per capita, inflation, unemployment, gross government debt, current account balance, international investment position and political control index of corruption and the rule of law. Asiri, Hubail (2014) also states that political risk has a significant impact on country assessments. Although insurance companies use similar criteria and resources, there are differences in various methodologies and aspects that insurance companies consider to be more crucial and which are less (this includes the subjective element of the evaluator when setting the criteria). Alternatively, it is often very difficult to compare facts that are rather abstract, such as the level of political stability, the riskiness of the business environment, etc. In addition to the empirically obtained values, the risk assessment of individual insurance companies will also reflect the vision of the insurance company, its goals and focus, which may differ from individual insurance companies.

The authors are of the opinion that the risk assessment of individual countries will help and in a positive sense influence the decisions of entrepreneurs in the implementation of their international transactions, so whether to enter the market or not, or under what other conditions. At the same time, in the case of the resulting riskier country, the exporter will be more cautious, better manage its risks, conduct further market and competitiveness research before deciding to enter the market. 


\section{Conclusion}

Insurance companies and exporters (respectively other entities dealing with the international environment) are aware of the impact of political risk on business success and give sufficient space to the analysis of political and economic risks. They must follow standard procedures in assessing risks and use reliable data sources that are used to derive them. It is no less important to correctly interpret the results of risk assessments (Asiri, Hubail 2014; McAleer, Hoti 2004). For this reason, the authors deduce possible differences in the final evaluation.

The risk assessment of insurance companies is not only used for the set parameters of individual insurance for the client, but is then also used for the improvement, analysis and development of new insurance products. Country risk assessment can contribute and influence the decisions of entrepreneurs in realizing their business activities.

Each insurance company sets its own criteria for assessing the risk of individual countries. The authors of the article performed an analysis of the risk assessment of individual insurance companies and the OECD. Then they compared the risk assessments of these insurance companies and the risk assessments of the OECD. Based on this, they found that these evaluations often have significant differences in assessment between countries. However, not only the comparison between the ratings of individual insurance companies, but mainly between the ratings of individual countries within one insurance company should be decisive.

In conclusion, it should be said that the presented article will be followed by other already prepared outputs, which will deal with the partial topics outlined in this text. One of them is the question of assessing the aspect of the impact of the granted country risk assessment on the demand for insurance, again supplemented by the aspect of the Czech exporter.

\section{Acknowledgement}

This research was financially supported within the VŠB-Technical University SGS grant project No. SP2020/77 (Risk Assessment in International Trade in Selected OECD Countries and Risk Minimization in the Context of the Czech Exporter).

\section{References}

[1] ASIRI, B. and R. A. HUBAIL, 2014. An Empirical Analysis of Country Risk Ratings. Journal of Business Studies Quarterly. 5 (4), 52-67. ISSN 2152-1034.

[2] ATRADIUS, 2020. Mapa rizik [online]. [cit. 15th September 2020]. Accessible from: https://atradius.cz/clanek/mapa-rizik.html\#.

[3] ATRADIUS, 2015. The STAR rating - Background information [online]. [cit. 15th September 2020]. Accessible from: https://atradius.cz/clanek/mapa-rizik.html\#.

[4] AU GROUP, 2020. Credit Insurance Market Survey [online]. [cit. 1st September 2020]. Accessible from: https://tcisigorta.com/media/0hloxo2c/credit-insurance-market-2020-augroup.pdf.

[5] BAR-NIV, Ran and D. L. BICKELHAUPT, 1986. Research in International Risk and Insurance: Summary, Synthesis, and Prospects. Journal of Risk and Insurance [online]. 53(1), 119-134 [cit. 4th July 2020]. ISSN 0022-4367. Accessible from: https://www.jstor.org/stable/252270.

[6] BERNE UNION, 2020. Export Credit \& Investment Insurance Industry Report 2019. Annual report of the export credit and investment insurance business of Berne Union Members [online]. [cit. 15th September 2020]. Accessible from: 
https://bublob.blob.core.windows.net/assets/Images/Berne\%20Union\%202019\%20Indust ry\%20Report.pdf.

[7] BÖHM, A a F. JANATKA, 2004. Pojištění úvěrových rizik v mezinárodním obchodě. Praha: Grada Publishing, a.s. ISBN 80-247-0816-7.

[8] CREDENDO, 2020. CREDENDO's Country Risk Assessment [online]. [cit. 17th July 2020]. Accessible from: https://www.credendo.com/rating-explanation.

[9] COFACE, 2020a. Economic Studies and Country Risks [online]. [cit. 17th July 2020]. Accessible from: https://www.coface.com/Economic-Studies-and-Country-Risks.

[10] COFACE, 2020b. Coface introduces CRAFT, a new forecasting tool to estimate growth in the Eurozone [online]. [cit. 20th August 2020]. Accessible from: https://www.cofacecentraleurope.com/content/download/177226/2919864/file/Panorama + Europe.pdf.

[11] COFACE, 2020c. Press release 31.3.2020 [online]. [cit. 17th July 2020]. Accessible from: http://www.coface.cz/Novinky-Publikace/Novinky/Pojistovna-COFACE-dava-ceskymfirmam-postizenym-dopady-pandemie-k-dispozici-zdarma-unikatni-obchodni-informace.

[12] COFACE, 2020d. Coface Risk Monitor [online]. [cit. 17th July 2020]. Accessible from: http://www.coface.cz/Sluzby-klientum/Kreditni-informace/Coface-Risk-Monitor.

[13] COFACE, 2020e. InfoIcon [online]. [cit. 17th July 2020]. Accessible from: https://icon.cofacecentraleurope.com/web/online/products/creditreportandmonitoring?19 $\&$ country $=$ AT \&language $=$ cs \& page $\mathrm{Id}=28$.

[14] COFACE, 2020f. Barometer. Country and sector risks barometer, Q2 2020. Coface Economic Research Team. 8 Juene 2020 [online]. [cit. 17th July 2020]. Accessible from: www.coface.com/Economic-Studies-and-Country-Risks.

[15] EGAP, 2020. Mapa rizik EGAP [online]. [cit. 20th August 2020]. Accessible from: https://www.egap.cz/.

[16] EULER HERMES, 2020a. Mapa rizika podle zemí. Jak se hodnotí riziko země? [online]. [cit. 30th August 2020]. Available from: https://www.eulerhermes.com/cs_CZ/ekonomicke-pruzkumy/mapy-rizika.html.

[17] EULER HERMES, 2020b. Sector risk methodology [online]. [cit. 30th August 2020]. Accessible

from: https://www.eulerhermes.com/content/dam/onemarketing/ehndbx/eulerhermes_com/cee/ pdf/sector-risk-methodology-euler-hermes.pdf.

[18] GLOVA, J., W. BERNATÍK and D. DANCAKOVA, 2019. Assessment of Changes in Country Risk Clustering of the EU Countries. AD ALTA-Journal of Interdisciplinary Research [online]. 9(2), 47-53 [cit. 1st November 2020]. Accessible from: http://www.magnanimitas.cz/ADALTA/0902/papers/A_glova.pdf.

[19] HOTI, S., 2003. The International Country Risk Guide: An Empirical Evaluation [online]. [cit. 30th August 2020]. Accessible from: http://www.mssanz.org.au/MODSIM03/Volume_03/B09/04_Hoti_International.pdf.

[20] LEE, Ch.-Ch., Y.-B. CHIU and Ch.-H. CHANG, 2013. Insurance demand and country risks: A nonlinear panel data analysis. Journal of International Money and Finance [online]. 36(C), 68-85 [cit. 20th August 2020]. ISSN 0261-5606. Accessible from: https://doi.org/10.1016/j.jimonfin.2013.03.009. 
[21] MCALEER, M. and S. HOTI, 2004. An Empirical Assessment of Country Risk Ratings and Associated Models. Journal of Economic Surveys [online]. 18(4), 539-588 [cit. 30th August 2020]. ISSN 0950-0804. Accessible from: https://doi.org/10.1111/j.09500804.2004.00230.x.

[22] MORTANGES, CH. P. and ALLERS, 1996. Political risk assessment: Theory and the experience of Dutch firms. International Business Review [online]. 5(3), 303-318, [cit. 30th October 2020]. ISSN 0969-5931. Accessible from: https://doi.org/10.1016/09695931(96)00012-1.

[23] OECD, 2020a. Country risk classification [online]. [cit. 15th July 2020]. Available from: http://www.oecd.org/trade/topics/export-credits/arrangement-and-sectorunderstandings/financing-terms-and-conditions/country-risk-classification/.

[24] OECD, 2017. Operational Procedures for the Country Risk Experts Group - December 2017 Revision [online]. [cit. 15th July 2020]. Accessible from: http://www.oecd.org/officialdocuments/publicdisplaydocumentpdf/?cote=TAD/PG(2017 )11/FINAL\&docLanguage=En.

[25] PETROVÁ, M., 2020. Insurable and Uninsurable Risks and their Classification from the Perspective of a Czech Exporter. In: BRANŽOVSKÝ, J. and J. PAVELEK eds. Proceedings of the 22nd International Conference MEKON 2020. Ostrava: VSB Technical University of Ostrava, pp. 154-161. ISBN 978-80-248-4410-7.

[26] POLÁK, J., M. BERANOVÁ and J. TABAS, 2011. Conception of risk in the international trade. In: The International Scientific Conference INPROFORUM 2011. České Budějovice: University of South Bohemia in České Budějovice, Faculty of Economics. pp 340 - 347. ISBN 978-80-7394-315-8.

[27] PRS GROUP, 2020. The International Country Risk Guide (ICRG) [online]. [cit. 15th July 2020]. Accessible from: https://www.prsgroup.com/explore-our-products/internationalcountry-risk-guide/. 